\title{
Translating Signs, Producing Subjects ${ }^{1}$
}

\section{Brett Neilson, University of Western Sydney}

This paper moves between two streets: Liverpool Road in the Sydney suburb of Ashfield and Via Sarpi in the Italian city of Milan. What connects these streets is that both have become important sites for businesses in the Chinese diaspora. More specifically, both are streets on which the signs displayed by Chinese merchants have become controversial. White residents who have felt displaced or discomforted by the ethnic entrepreneurialism in these areas have imagined that requirements for bilingual signage would diminish their unease. In Ashfield, this has resulted in the introduction of a series of measures by local government to encourage Chinese shopkeepers to change their signage, including changes to regulations, information kits and annual awards. In Milan, there is high public pressure to introduce legislation making Chinese-Italian signs mandatory. What interests me is how such measures assume the process of translation to institute an equivalence between languages. Drawing on the work of Naoki Sakai (1997), who contests the proposition that discrete languages exist before the act of translation, I question the supposition that such measures serve to encourage interethnic dialogue, cultural hybridity and social harmony. Far from establishing a bridge between languages, translation divides them. With regards to Liverpool Road and Via Sarpi, this has tangible social effects, not least as concerns the production of subjectivity in relation to understandings of community and citizenship.

\footnotetext{
1 This paper was initially prepared for the panel entitled 'Translation and Citizenship' at 'Lingua, cultura, cittadinanza,' a conference organised by the Facoltà di Lingue e Lettere Straniere Moderne of the Università di Bologna, 4-5 Feburary 2008. I would like to thank the panel organisers and participants (Giuliana Benvenuti and Sandro Mezzadra) for the invitation to participate in this event, as well as the other panel participants (Étienne Balibar, Naoki Sakai and Jon Solomon). An Italian version of this article will appear in a volume published by Odoya.
}

PORTAL Journal of Multidisciplinary International Studies, vol. 6, no. 1, January 2009.

'The Space Between: Languages, Translations and Cultures': Special Issue edited by Vera Mackie, Ikuko Nakane, and Emi Otsuji. 
It is doubtless a mistake to assume the production of subjectivity takes place solely within the constraints of language. Key structuralist accounts emphasized the role of language in splitting the subject between the énoncé and the énonciation, the subject who speaks and the subject who is spoken about (Benveniste 1971; Lacan 1977). As powerful as these accounts were, particularly for exploring the relation of subjectivity to ideology, they tended not to account for the multiplicity of human languages. Consequently the nexus of translation and subjectivity was sidelined in the resulting debates. Poststructuralist and postcolonial approaches met this challenge by taking up issues of contact, 'inbetweenness' and hybridity, all the time widening the unit of translation from language to culture (Pratt 1992; Bhabha 1994). At the same time, there was an effort to broaden the discussion on the production of subjectivity to encompass more transversal approaches, taking into account affects, experiences and the like as well as processes of cultural signification (Guattari 1995). Added to this was a new emphasis on the role of contemporary capitalist transformations in the production of subjectivity. The growing tendency for capitalist production to involve linguisticsymbolic communication as well as affective relations between humans (aside from the production of material commodities) was a key factor here. As Read (2003: 159) explains: 'Capital no longer relies on cooperative networks of the reproduction of subjectivity that are exterior to it; instead, it directly produces and profits from the production of subjectivity, and this transformation has been imposed on it in part by the productive powers of subjectivity.' How to integrate the dynamics of translation into such an analysis of the production of subjectivity? The example of shop signage provides a strategic site of investigation. This is because the shop, apart from being a place of commodity exchange and profit generation, is a site of linguistic transactions and affective relations. As clear from the discussion below, it is a feeling of discomfort that accompanies the cognitive experience of incomprehension that turns many residents against the presence of street signs in Chinese ideograms.

The existence of such signs on streets like Liverpool Road and Via Sarpi is an effect of particular forms of Chinese entrepreneurialism that have spread with recent migratory movements. Although there are long standing Chinese communities in Sydney and Milan, dwelling in the latter case in the vicinity of Via Sarpi, the intense entrepreneurial activity along these streets is a phenomenon that dates from the 1990s. There is a need to understand these developments, along with the growth of similar entrepreneurial 
pockets in other parts of the world, with respect to the rapid economic and cultural transition experienced in China since the 1990s. Part of this analysis must be a consideration of the effects of China's transition on migratory patterns, both internal and external, as well as on the changing role of Chinese language in the world. The issues regarding dual language signage must thus be analysed with a global regard. Far from being merely a matter of local or national policies regarding language and cultural diversity, the institution of such signage involves a regime of translation that not only structures the production of subjectivity in the present neoliberal conjuncture but also influences the geocultural configuration of the world.

\section{Liverpool Road}

A stroll down Ashfield's major shopping street is not the same experience it was at the beginning of the 1990s. At that time, Liverpool Road hosted a mix of Anglo, Italian and Greek shopping, reflecting the ethnic groups that composed the area's population. Today about eighty-five percent of the shops along the street are Chinese small businesses, primarily restaurants and supermarkets. The prevalence of Chinese migration to this part of Sydney is directly linked to the Tiananmen Square massacre, that violent political rupture that marked the beginning of China's neoliberal transition (Wang 2003). At the time, the Australian government granted permanent residency to some 42,000 Chinese students who were studying in the country. These visa holders were then able to bring out family from China under Australia's then family reunion migration scheme, meaning that numbers swelled to an approximate 100,000 by the end of the 1990s. Most of these migrants settled in Sydney and many made Ashfield their home. Due to the preponderance of Shanghainese among them, the area is sometimes known as Little Shanghai.

As opposed to the downtown Chinatown, established for well over a century as place where white Australians can go to eat Cantonese food, this is a place where it is possible to find restaurants serving cuisines from other regions of China, including, not surprisingly, Shanghai cuisine. Many of these establishments, which have erected street signs written exclusively in Chinese, cater to the local migrant populations as well as the increasing numbers of tourists who visit Sydney from mainland China. They are also magnets for cosmopolitan gourmets, who come mostly from the wealthier areas to the north and the east of the city, to sample the meals these restaurants have to offer. 
Recently, however, some members of the local white population, which has lived in the area for many years and experiences a sense of displacement due to the influx of Chinese migrants, have begun to express discomfort about the lack of street signs in English. A similar area to the south of the city, Hurstville, has legislated to make English signs mandatory, stipulating that Chinese characters on a sign cannot be larger than the letters of the Latin alphabet that comprise the English text. Ashfield has now followed suit. The local government has changed the regulations about signs, employing a Chinese speaking community worker and consulting academics to try to increase the presence of the English language on the suburb's main street.

In a report entitled Contact Zones, Amanda Wise (2004: 4) presents the results of research that investigated how elderly Anglo-Celtic and other long-term residents of Ashfield 'are experiencing cultural diversity and the rapid changes that the recent wave of Chinese migrants have brought to the suburb.' The study discovers that the 'most prominent area of discomfort among not only Anglo-Celtic senior citizens but also older long-term residents of other backgrounds - especially Greek, Italian, Polish and Indian - had to do with the predominance of non-English signage without translation along the Ashfield main street' (13). Apart from these street signs, residents expressed dismay at the presence of Chinese language posters covering shop windows, lack of design quality, the prevalence of phone card advertisements and Chinese language menus displayed in the windows of restaurants. Also reported were feelings of discomfort with the inability of some Chinese shopkeepers to speak English, their use of personal space, manners and social rituals. The report, which is careful also to offer positive stories about the experiences of long-term Ashfield residents in Chinese shops, concludes that these factors are perceived as an 'alienating barrier' by many older community members. It goes on to recommend an approach that would not ban Chinese signage along Liverpool Road but rather introduce 'a policy of translation for all signage in Ashfield where possible' (14).

As a result of the Contact Zones report, Ashfield Municipal Council began to work with Wise in the frame of a larger project to realise the goal of increasing the presence of translated signs along the street, assisting Chinese shopkeepers to make their premises more amenable to non-Chinese customers and generally enhancing the contact between the Chinese and other residents of Ashfield. Apart from intercultural meetings, this 
initiative involved the production of an information kit for Chinese shopkeepers, the employment of a Mandarin-Shanghainese speaking community worker and the institution of the annual Welcome Shop Awards. The bilingual information kit instructs Chinese shopkeepers to 'combine beauty with business' and offers examples of good signage practice (including professionally designed Chinese ideograms and English characters of equal size), window presentation and store layout. It also provides hints about how to treat non-Chinese customers, including the suggestion to smile and establish eye contact with them. The Welcome Shop Awards provide civic recognition for Chinese shopkeepers and restaurateurs who have heeded this advice. Nominations can be made by any resident in the area, and prizes include plaques and paid advertising in local newspapers.

These are non-coercive measures to achieve dual language signage as well as other modifications to the shops along Liverpool Road and adjacent streets. Not surprisingly, the question of the translation of shop signs is controversial. When neighbouring Marrickville Council proposed to make such translation mandatory, one of the Councillors, Saeed Khan, described the plan as 'outright racist,' saying: 'I don't mind if every business has an English name, but to force shops to translate every single word on their shopfront into English is a stupid, divisive idea' (quoted in Murray 2006). In the Contact Zones report, Wise heads off such criticism in a number of ways. First, she acknowledges this is a controversial matter. Second, she makes it clear she does not support a ban on foreign language signage in Ashfield. Third, she draws on the dominant, but threatened, social ideology of multiculturalism to support her claims. Noting that not only Anglo-Celtics but also other ethnic groups in the area, including non-Mandarin-Shanghainese speaking Chinese, are discomforted by the signs and that English is 'the only practical common language,' Wise writes: 'Far from being a xenophobic, anti-multicultural response, requiring English translations encourages multiculturalism. Translations are more likely to attract a diverse clientele into the shop creating more possibilities for intercultural and interethnic learning' (2004: 15).

There is much to unpack in this statement. What I want to remark, at this stage, involves less the status or foreignness of the Chinese language in this context than the role of English as a linguistic vehicle for encouraging 'multiculturalism.' Certainly, in the case of Chinese signs that are translated into English, it is necessary to note the flattening of 
an ethnic community language into the national lingua franca. There can be no doubt that translation of signs into 'the only practical common language' reinforces the status of English as Australia's national language. English figures here as a kind of 'general equivalent' that is imagined as 'likely' to facilitate 'intercultural and interethnic learning' between the Chinese and the Anglo-Celtic, the Chinese and the Italian, the Chinese and the Indian, and so on. The use of the term 'general equivalent' here, which is the term Marx (1887) uses to describe the role of money within the capitalist economy, is not accidental.

After all, the shops along Liverpool Road are part of the world of business, since they buy and sell commodities in the marketplace. The emphasis on linguistic communication (street signs, greetings) as well as affective comportment (smiles, gestures, bodily distance) in the materials distributed by Ashfield Council to Chinese shopkeepers relates not only to the role of these factors in promoting intercultural relations. But also, given the commercial setting, it reflects their growing importance in a service and consumer oriented economy increasingly driven by immaterial production. One consistent argument provided in these materials as to why Chinese merchants should abide by their guidelines is that failure to do so might result in loss of customers. Interestingly, in Hurstville, the area in the south of Sydney where government legislated to make Chinese shops display dual language signs, turnover in these businesses has increased by ten to twenty percent (Duffy 2006). Similar figures are not available for Ashfield, but perhaps the presence of tourists from China would make a difference. In any case, the parallel between the unilateral regime of translation that in 'multicultural' Australia renders all other languages as English and the capitalist system that translates all 'relative' values into the general equivalent of money is no theoretical nicety but a practical matter with measurable effects.

\section{Via Sarpi}

On 12 April 2007 a full scale riot broke out on Milan's Via Sarpi. A home to Chinese migrants since their initial arrival in Italy in the 1930s, the quartiere in which this street is located has experienced a twenty-four fold increase in Chinese population since 1986. At the same time, it has been undergoing a rapid process of gentrification, meaning that the local white communities, who still comprise ninety percent of the population, have become increasingly concerned about the proliferation of Chinese businesses. These are 
primarily wholesalers who sell cheap goods from China and attract large trucks into the area's narrow streets. Partly due to the agitation of residents' groups such as the Associazione ViviSarpi, the Comune di Milano legislated in 2002 to restrict the hours in which the loading and unloading of materials from motor vehicles is permitted in the area. In the two months prior to 12 April 2007, the policing of these regulations had been stepped up and the installation of closed circuit security cameras had been announced to monitor 'illegal activities' in the vicinity of Via Sarpi. Some members of the Chinese community were so upset about these 'zero tolerance' measures, which made it near impossible for wholesalers to conduct their business, that they prepared banners to stage a sit-in at Palazzo Marino, the seat of the city government.

This protest was never to occur. The riot started with an everyday dispute over a parking fine. Ruowei $\mathrm{Bu}$, a twenty six year old Chinese woman, parked her car on Via Sarpi while her husband unloaded shoes into their shop. She was issued with a fine. An argument ensued, which quickly escalated to push and shove when the police confiscated the car's registration papers. By the time the police decided to take the woman and her crying child away, a crowd had gathered. Word spread that Ruowei had been hit by police and dozens of people began to stream on to the street, some carrying Chinese flags. Police called for reinforcements and, as the banners prepared for the Palazzo Marino protest appeared, the violence gathered pace. Before the day was out, cars had been overturned, fourteen riot police had been taken to hospital, the Chinese consul had appealed for calm and Chinese Premier Wen Jiabao had demanded a report on the confrontation. The reporting of the event in the Chinese news media prominently featured images of Milanese police trampling on Chinese flags.

The reasons for this conflict are complex and certainly cannot be boiled down to the question of street signage along Via Sarpi, although in the wake of the riot, as in Sydney's Ashfield, this would emerge as a hot point for debate. As Cologna (2008) points out, while Via Sarpi has emerged as an important site for Chinese commerce, less than ten percent of the Chinese in Milan live in its vicinity. To some extent, the tensions in the area are a result of conflicts of interest between local residents and businesses, which have acquired a racialized character. Patterns of Chinese migration to Milan have been shaped by the fact that the initial migrants who established themselves in the city in the 1930s came from villages in the district of Qingtian, located in the mountains 
behind the city of Wenzhou in the south of Zhejiang province (Thunø 1999). When, in the 1980 s, the economic boom in this area occasioned new opportunities for migration, mostly through clandestine means, the community in Milan was one among others in Europe that accepted the newcomers. Often the new migrants, who were generally less skilled individuals than those making their way to Australia or the United States, were subjected to a period of debt bondage before they were able to make their way in the wider economy (Cologna \& Mancini 2001). Not only did whole villages in Qingtian begin to empty out, but across the 1990s, with the growth of internal migration in China, the composition of the migration flows also began to change. For instance, the movement of workers from Qingtian to the city of Sanming in Fujian province meant that migration routes also opened from this city to Milan. At the same time, paths opened through Russia for the movement of workers from the northern industrial city of Shenyang. Many of these migrants, primarily women, would become domestic workers for well-off families in Milan.

During the 1990s, the role of Chinese migrants in the Italian economy also began to change. The growing number of arrivals meant that not all new migrants could be accommodated within the industries traditionally staffed by Chinese workers-e.g., the manufacture of leather goods or the restaurant sector. Many new migrants established themselves as travelling salespeople, selling cheap goods manufactured in China's industrial boom. From here began the growth of the businesses along Via Sarpi. Some of the salespeople were able to set themselves up as wholesalers, initially supplying to other Chinese but expanding their market to include migrants of other nationalities, Italians active in small town markets and even merchants who would come from as far as Switzerland or France to stock up on cheap wares (Cologna 2008).

The events of 12 April 2007, however, cannot simply be understood as the result of a hostile local reaction to the urban inconveniences occasioned by the growth of the Chinese wholesaling business. As Sossi (2007) explains, Milan has been the site of development for particular 'forms of control' that have acquired 'an independent and autonomous modality of existence' from that which is usually considered 'normal or normative' (my translation). Sossi refers not only to the political influence of the Northern League, in many ways an anti-immigrant party, but also to strategies of economic control operating at the micro level: 
It is not by chance that these forms of control are developing in Milan, one of the most productive cities in Italy. The control of the economy and in particular of the Chinese wholesalers occurs through the invention of strange forms of protectionism which are comprehensible only if one understands how this autonomous form of economy, far from being completely liberal, is directed toward 'ethnically' diverse people ... These forms of control are ever more stringent but also ever more invisible. It is thus not by chance that the revolt in the Chinese quarter exploded because of a parking fine, since the Municipal Police in Milan have become that form of control deputised to establish new borderlines (my translation).

In the case of Via Sarpi, these borderlines have been established through forms of policing that restrict traffic and parking in ways that force Chinese wholesalers and their customers to move goods in and out of the area in large trolleys. Since the events of 12 April 2007, these forms of control have only escalated. Clampdowns on the use of trolleys have increased, the Comune di Milano has announced the closure of the area to all traffic from September 2009 (with closed circuit surveillance and loading and unloading of goods permitted only in severely restricted hours), and negotiations are underway to ban wholesaling in the area and move the Chinese merchants to the periphery of the city (Gallione 2008).

Interestingly, the call for these measures on the part of local Italian residents has been accompanied by the demand that all street signs in the area should necessarily feature Italian translations. A motion passed by the Consiglio di Zona 1, the relevant governing body for the Sarpi area, makes the following recommendation to the Comune: 'With regard to shop signs, advertisements and any other visible messages, apart from a general redesign, they should always feature characters in the Italian language' (Mozione 2008, my translation). Apart from the fact that many signs along Via Sarpi already contain Italian translations, this motion imagines such a requirement to be consonant with a series of measures that seek to limit the activities of Chinese businesses in an area where they have been established for over eighty years. How can it be that in the case of Liverpool Road bilingual signs are imagined as a means of creating harmony and intercultural learning, while, in the case of Via Sarpi, they accompany new forms of policing, control and cultural segregation?

\section{Translation and citizenship}

To answer the above question it is necessary to jump to the global level. The presence of Chinese merchant communities, along Liverpool Road as well as Via Sarpi, is not solely related to changes in the national level in Australia and Italy, although an analysis of these changes must certainly inform any adequate account of the cultural 
transformations along these streets. In the early 1970s, Australia moved away from the so-called White Australia policy, which importantly restricted immigration through the application of a language test, toward its current practices of strict border control and selectively filtered immigration through the so-called points system. During the same period, Italy began its transition from an emigration to an immigration country, although, like the introduction of the official government policy of multiculturalism to Australia in the early 1970s, this is by now a process largely played out, if not one that has entered into crisis. One sign of this crisis is visible in debates surrounding citizenship. The introduction in October 2007 of the Australian Citizenship Test to assess the knowledge of Australian history, values and traditions for all who wish to become citizens, like the proposal that immigrants acquiring Italian citizenship will have to pass a test to show adequate knowledge of the Italian language and culture, are symptomatic of this situation.

There are many things one can say about such measures, which are not unrelated to the demands for dual language signage along Chinese-dominated streets in Sydney and Milan. Most importantly, they signal a transition in debates about citizenship, which once focused on universalistic issues such as democracy, political rights and responsibilities, but now shift to include concerns about culture, which were formerly confined to the particular. In a sense, one can say that these debates have pushed to a limit the traditional paradox of modern citizenship, that is, that it invoked universal rights but only in a particular territory. With the explosion of this paradox, the question of translation has come to the fore. Since, in conceptual terms, the question of translation evades, or better cuts through, the unresolved (and quite possibly) irresolvable aporia of the universal and the particular. We can signal this by indicating that translation is instead a problem of the common and the singular. Here, the common is not understood as the sensus communis, which Kant, in his third Critique, defined as that 'subjective principle ... which determines what pleases or displeases, by means of feeling only and not through concepts, but yet with universal validity' (1982: 206). Rather it describes the experience of living in, through and between the transversal relations that compose the world. To experience the common is to approach 'the world as a heterogeneous space of intermundial intercourse, rather than thinking in the space of a community gathered around a univocal set of rules' (Karatani 2005: 99). In other words, the common designates the space between languages, the space between cultures. 
The final section of this paper returns to this question of the common. Since translation is a practice as well as an epistemic relation, it is important also to discuss it in practical terms, by no means limited to the interactions between languages. Translation, in this sense, is a 'relational encounter between entities, affective modulations, the visible and invisible, perceptions and imperceptions, communication and the non-communicable' (Neilson \& Rossiter 2008: 64). With respect to patterns of Chinese migration in Australia and Italy, there is a need to consider how they relate to wider geopolitical, economic and cultural shifts as well as the relations between these processes on different geographical and temporal scales and in different affective registers.

What occurred on Milan's Via Sarpi, as much as it relates to the specific forms of cultural and economic control exercised in that city, must also be analysed in its transnational dimensions. At stake are not simply the local forms of protectionism, which are filtered through Lombard cultural mores, sometimes with a more racist face than others. These protectionist impulses are formed partly in reaction to the growth and international expansion of the Chinese economy, announced everywhere in Italy from the popular books of Federico Rampini (2006) to the erudite historical analyses of Giovanni Arrighi (2007). But this same transition lies behind the current wellspring of Chinese migration and not only on the international scale. It is important to remember that the bulk of Chinese migration has been rural-urban movement within the country and regulated by the so-called hukou system of housing registration (Cheng \& Selden 1994). To understand the events on Via Sarpi, it is necessary to ask who gets to be a Chinese wholesaler in Italy, how, where and by whom are the goods they sell produced, how do the trade networks that bring these goods to Europe function, and so on.

Relevant in this regard is that the area from which the vast majority of Milan's Chinese migrants hail was the centre of the so-called 'Wenzhou model' of industrial development in the 1980s and 1990s (Parris 1993). Based on household industries, wage labour, commodity markets and self-organised credit associations, the rapid economic growth in Wenzhou produced the wealth that facilitated the migration of many to Europe, particularly Italy. Also significant are the changes to internal migration patterns to and from Zhejiang province, in which Wenzhou is located. In the period 1990-1995, the province was the seventh largest exporter of migrant labour to other provinces of China, including Zhejiang village, the largest migrant enclave in Beijing 
(Xiang 2005). By 1995-2000, it had become the third largest net importer of migrants from other Chinese provinces, and by 2000-2005 the second (Chan 2008). Clearly, the province's development, which fuelled the migration from Wenzhou to cities like Milan, was itself enabled by labour migration within China.

Linked to the appearance of new borders around the Sarpi area is thus the establishment of new borders that regulate migration within the Chinese territory itself. As anthropologist Pun Ngai (2005) has shown in the case of the Shenzhen Special Economic Zone, this is crucial to productive system now in place in China. Such a fracturing of territory, or what Ong (2005) describes as graduated sovereignty, clearly has parallels in the proliferation of internal borders in other continental and national spaces, not least in Europe itself, as thinkers such as Étienne Balibar (2004a) have effectively demonstrated. An understanding of this development is crucial not only to the analysis of internal migration and its importance to current productive practices in China. It is also important for the understanding of what is described above as the exhaustion of the paradox of modern citizenship, conceived as universal but also as imposed in a particular, territorially homogenous and neutrally bordered, political space.

Another related issue concerns language policy in the People's Republic of China. In 2001, the government adopted standard Mandarin (based on the Beijing dialect) or Putonghua as the official language in order to meet the challenges of a growing market economy and the increasing interaction between people from different parts of the country. Neither the Shanghainese in Ashfield nor the Wenzhounese in Milan are speakers of Putonghua, although many can understand this standard language. Both speak dialects of $\mathrm{Wu}$ Chinese, which in the case of the Wenzhounese dialect is tricky for many other Chinese to comprehend. This is not an issue for written language, such as that appearing on signs along Liverpool Road and Via Sarpi, since both of these $\mathrm{Wu}$ dialects use the same simplified ideograms as Putonghua. But the question of the growing dominance of Putonghua is a pressing issue, especially as regards the maintenance of dialects and minority languages in China (Guo 2004; Poa \& LaPolla 2007). The introduction of Putonghua as the language of instruction in local and international schools in Cantonese speaking Hong Kong is highly controversial, and, as Davison and Lai (2007: 119) argue, this involves 'both global economic and social- 
ideological factors.' Similarly, in the wider Chinese diaspora, the growing status of Putonghua as a language of trade and business is making itself felt.

Cologna (2008) notes that many of the women who migrated from Shenyang to Milan to work as domestic helpers have lately found employment teaching Putonghua to the children of Wenzhounese immigrants. The children of Shanghainese immigrants in Ashfield also learn Putonghua, now Australia's second most spoken language, through the New South Wales school system. Meanwhile, several key Chinese education and cultural agencies have decided to encourage the worldwide learning of Putonghua. Among these are the Beijing-backed Confucius Institutes, of which over two hundred and sixty currently exist in seventy different countries. Lo Bianco (2007: 4-5) links the expansion of Chinese language learning to China's new economic position, seeking to understand its spread in terms of patterns of influence that relate to "contemporary forms of "empire" and "domination" under conditions of globalization, the decline of exclusive sovereignty and economic interdependence.' At a time when we hear so much about 'global English,' it is worth keeping this aggressive linguistic reality in mind. It is insufficient to understand the introduction of dual language signs along Liverpool Road and Via Sarpi as the imposition of a dominant upon a minority language. In reality, the languages of the communities who erect these signs are also under threat from the global expansion of Putonghua in the twenty first century.

\section{On co-figuration}

To return to the initial scene of Chinese signage in Sydney's Ashfield, this background puts a new perspective on the situation. No longer can we understand the introduction of dual language signs solely as the flattening of a minority into a national language under the aegis of Australian multicultural ideologies of harmony, although it is important to keep this reading in play. It is probably apposite to note that the teaching of Putonghua among China's ethnic minorities is also promoted under the ethos of 'harmonious society,' which since the 2005 National People's Congress has emerged as the principal socio-economic vision of the Chinese government. What is being legislated in the case of the Sydney signs, however, is something more than harmony, which has certainly become a keyword for programs of social inclusion, no matter how differentially they may be implemented the world over. At stake is also the co-presence of two dominant global languages, which vie with each other, but also enter into unexpected forms of 
complicity - with China increasingly emphasizing the learning of English (especially among university graduates) and English-speaking countries, not least Australia with its fluent Mandarin speaking Prime Minister, promoting the learning of Putonghua. How then are we to read these dual language signs in a dynamic global context where the endless rerun of universality and particularity through the political figure of the citizen has been short-circuited by new patterns of intimacy, sovereignty and partitioning?

I am not angling for some enthusiastic reading of these signs as ciphers of East-West harmony, competition, interpenetration or the like. I do not want to abandon the critical impulse, especially given the practices of ethnic bordering that accompany the demand for Chinese signs on Via Sarpi to feature dual script in Italian, itself a national language with global reach, although neither on the scale of English nor Putonghua. What needs to be questioned, especially given the recommendations that the characters of the two languages be accorded the same size, is the very notion of interchangeability that these signs pose. At stake here is what Naoki Sakai (1997) calls co-figuration-the very schema that allows the representation of translation as the passage between two equivalents that resemble each other and thus makes possible their determination as conceptually different. Co-figuration involves the negotiation and reification of the difference between a familiar and unfamiliar language. Although this relation cannot be perceived as symmetrical, its terms can be made available for a comparison 'in which both the familiar and the unknown are rendered representable and come to be represented by their respective figures' (Sakai 1997: 34). Co-figuration thus entails the representation of translation as a movement between two already separate and internally homogeneous languages, which, in their interchangeability, allows the constitution of the figure of 'us' in the projective imagining of the figure of 'them.'

For Sakai, the 'practice of translation' is 'radically heterogeneous to the representation of translation' (1997: 15). Through the practice of translation, 'the incommensurability as difference that calls for the service of the translator in the first place is negotiated or worked on' (14). Translation is 'just like other social practices that render the points of discontinuity in the social formation continuous' (14). Only after translation, does it become possible 'to represent the initial difference as an already determined difference between one language unity and another' (14). The representation of translation thus 
involves the erasure of the oscillation, indeterminacy and encounter with the untranslatable involved in the practice of translation:

\begin{abstract}
Only in the representation of translation can we construe the process of translation as a transfer of some message from "this" side to "that" side, as a dialogue between one person and another, between one group and another, as if dialogue should necessarily take place according to the model of communication. Thus the representation of translation also enables the representation of national or ethnic subjects, and, in spite of the presence of the translator, who is always in between, translation, no longer as difference or repetition but as representation, is made to discriminatorily posit one language unity against another (and one cultural "unity" and another). (15)
\end{abstract}

It is precisely such a representation of translation that is found on dual language street signs, whether understood to facilitate intercultural dialogue, as in the case of Liverpool Road, or to reinforce borderlines between cultural groups, as in the case of Via Sarpi. Not only does such a representation of translation function according to the model of communication, prioritizing the transmission of a message to a certain language group (this shop sells that), but it also obscures differences within the unities figured as equivalents, for example, differences of dialect. Furthermore, as Sakai argues of the schema of co-figuration, these signs allow a national community to constitute itself as a subject by 'making visible the figure of an other with whom it engages in a translational relationship' (1997: 15-16).

To further examine the question of translation and subjectivity, I would like to ask how this schema of co-figuration relates to the vision of co-citizenship that Balibar (2004a) advocates as a means of thinking of citizenship not only in terms of sovereignty and formal political belonging but also as a differentiated and partial notion that might be shaped in various ways to provide cultural, political and social rights. The concept of co-citizenship seeks to work over and across the kind of representation of translation Sakai finds implicit in the schema of co-figuration, imagining the production of political subjectivity within a civic and civil space where the stranger is not recognised as the enemy. At stake is the question of 'access to rather than simply entitlement to citizenship' (Balibar 2004a: 132). Balibar attempts to imagine a form of democratic political membership, which, while necessarily bounded, is continuously recreated in a politics of civility in which border crossing becomes the very substance of citizenship. Furthermore, he imagines this civility to be played out in terms of a 'conflictual model of the process of translation ... where differences are neither denied nor absolutized' (2004b: 21). How does such an understanding of citizenship relate to the politics of 
translation discussed by Sakai? More precisely, is the co- in co-figuration the co- in cocitizenship? Asking this question takes us to the heart of the nexus of translation and citizenship embodied in the debates about bilingual signs that provide the focus of this paper.

To interrogate the co- in this way is to raise the question of the common. It is to move into a space and time where relations precede identities and differences and can be anchored to neither a stable subjectivity nor a given human nature. Yet it is also to remember that the common is equivalent to neither the universal nor the public - that it implies, and issues the challenge to construct, a relation of value that does not pass through the general equivalent as described by Marx. It is thus neither a system of equality — which in its modern constitutional format was always vouchsafed by a simultaneous appeal to hierarchy_nor of civility, which although a relational notion assumes a bounded political space in which hospitality might be extended or tolerance exercised. Just as importantly, it is not a feature or capacity of community, whether understood as an ethnicized or nationalized organism or as an irreducibly differentiated construct (Nancy 1991; Esposito 1998). Nor is the common, I might add in a counteractive note to some of the more recently pervasive modes of conceiving it, a positive and creative flux of vitalistic energy that is without content, open to appropriation, and thus refuses to reckon with the power of the negative that fails to disappear with the exhaustion of dialectical thought. To make only half a joke in Italian, I would like to call this question of co-figuration, co-citizenship and the common, the problem of the cococo (the term is a contraction of contratto contratto contratto, contract contract contract, and is widespread to refer to the figure of the precarious worker).

Only half a joke, I say, since the labour contract is central to the presence of migrants in countries like Australia and Italy, whether under the terms of Australia's 451 visa (for the entry of skilled migrants with employer sponsorship) or Italy's Bossi-Fini laws (where it provides the migrant's immunization against deportability). The co- in contract posits subjects who enter into an agreement on equal terms, a formal equality, which is then played out in terms of the production of surplus value, both absolute and relative, which involves relations of exploitation. It is such a contractual arrangement, I would say, that underlies the co-figuration present on the signs in Sydney's Ashfield. In 
so far as these acts of translation promise recognition for an appropriate performance of difference, they embody what might be called the contract of Australian multiculturalism: a contract that guarantees the official recognition of differences that will not disturb the social ordering but also, as became clear in the Cronulla riots of December 2005 (involving violence against and on the part of Arab men), the continued racialization of differences that do disturb. If the Chinese merchant remains a disturbing difference in Milan, it is not necessarily due to the presence of a similar multicultural pact. But here again the labour contract is a central question, since in play is the question of which migrants get to become a small entrepreneurs in this most commercial of Italian cities.

To return to the question about the co- in co-figuration and co-citizenship then, it is necessary to answer both yes and no. Co-figuration assumes a time and space of beingalongside that can then generate infinite evaluations on the basis of differences. It is not necessarily free of the formal equality of the contractual agreement that precedes the act of labour exploitation. Likewise, co-citizenship, while it implies a mode of civil cohabitation that moves beyond the binary of citizen and foreigner, is not, insofar as it involves 'at the same time community and universality,' sufficient to vouchsafe the construction of the common. Balibar himself is clear that the emergence of cocitizenship will be a 'long and hazardous process,' which will not necessarily escape the 'intrinsic antinomies' of citizenship - that is, the tensions between rights and duties, membership and exclusion, participation and representation, formal equality and substantive inequalities, and so on (2004b: 21-23). If the co- in co-figuration is the coin co-citizenship, it is not necessarily the co- of the common. To construct the common it may be necessary to become co-foreigners rather than co-citizens, to practice and imagine ways of being alongside or together that do not refer to the contractual model of recognition and rights and/or its correlate sovereign arrangements. It is to invent another mode of figuration, let's call it transfiguration, based in the realization that translation is never a finished practice - as implied by the finality of translated street signs - but a permanent process that abdicates the sovereign position of arbitration/neutrality to produce a space and time where the general equivalent is bypassed and the encounter with difference never complete. 


\section{Reference List}

Arrighi, G. 2007, Adam Smith in Beijing: Lineages of the Twenty-First Century, Verso, London.

Balibar, É. 2004a, We, the People of Europe: Reflections on Transnational Citizenship, Princeton University Press, Princeton.

Balibar, É. 2004b, 'Europe as Borderland.' Online, available: http://www.ru.nl/socgeo/colloquium/Europe\%20as\%20Borderland.pdf(Accessed 4 November 2008).

Benveniste, E. 1971, Problems in General Linguistics, trans. M. E. Meek, University of Miami Press, Coral Gables.

Bhabha, H. 1994, The Location of Culture, Routledge, London.

Chan, K. W. 2008, 'Internal Labor Migration in China: Trends, Geographical Distribution and Policies,' United Nations Expert Group Meeting on Population Distribution, Urbanization, Internal Migration and Development, Department of Economic and Social Affairs, United Nations Secretariat, New York, 21-23 January.

Cheng, T. \& M. Selden 1994, 'The Origins and Social Consequences of China's Hukou System,' The China Quarterly, no. 139, 644-68.

Cologna, D. 2008, 'Il “caso Sarpi” e la diversificazione crescente dell'imprenditoria cinese in Italia,' in Un dragone nel Po: La Cina in Piemonte tra percezione e realtà, (eds) R. Cima et al. Edizioni dell'Orso, Torino. Online, available: http://www.codiciricerche.it/documenti/30\%20\%20dragone\%20po\%20DC\%20art.pdf (Accessed 19 December 2008).

Cologna, D. \& L. Mancini 2001, 'Percezione dei diritti di cittadinanza e forme di partecipazione sociale e politica degli immigrati cinesi a Milano,' in Problemi della produzione e dell'attuazione normativa - vol. iv - I diritti difficili nel sistema giuridico, (eds) A. Artiosi et al, GEDIT Edizioni, Bologna. Online, available: http:/www.cirfid.unibo.it/murst40-97/40-97/SezioneII/ParteV/5.1/ColognaMancini new.doc (Accessed 19 December 2008).

Davison, C. \& W. Y. W. A. Lai 2007, 'Competing Identities, Common Issues: Teaching (in) Putonghua,' Language Policy, no. 6, 119-34.

Duffy, M. 2006, 'Non-English Signs a Barrier for Many,' Sydney Morning Herald. 28 October. Online, available: http:/www.smh.com.au/news/opinion/nonenglish-signs-a-barrier-formany/2006/10/27/1161749313595.html (Accessed 14 June 2008).

Esposito, R. 1998, Communitas: L'origine e destino della comunità, Einaudi, Torino.

Gallione, A. 8 May 2008, 'Chinatown solo a piedi, al Girasole spuntano ideogrammi,' La Repubblica. Online, available: http://milano.repubblica.it/dettaglio/Chinatown-solo-a-piedi-al-Girasolespuntano-ideogrammi/1455322 (Accessed 20 June 2008).

Guattari, F. 1995, 'On the Production of Subjectivity,' in Chaosmosis, trans. P. Bains, Power Institute, Sydney, 1-31.

Guo, L. 2004, 'The Relationship between Putonghua and Chinese Dialects,' in Language Policy in the People's Republic of China, Theory and Practice since 1949, (eds) M. Zhou \& H. Sun, Kluwer, Boston, 45-54.

Kant, I. 1982, Critique of Judgement, trans. J.C. Meredith, Clarendon Press, Oxford.

Karatani, K. 2005, Transcritique: On Kant and Marx, trans. S. Kohso, Cambridge, MA.

Lacan, J. 1977, Écrits: A Selection, trans. A. Sheridan, Tavistock, London.

Lo Bianco, J. 2007, 'Emergent China and Chinese: Language Planning Categories,' Language Policy, no. 6, 3-26.

Marx, K. 1887, Capital, vol. 1, trans. S. Moore and E. Aveling. Online, available: http://www.marxists.org/archive/marx/works/1867-c1/index.htm (Accessed 14 June 2008).

Mozione sulle problematiche del quartiere Sarpi-Canonica e per la Realizzazione della ZTL in Via Sarpi 2008, Online, available: http://www.partecipami.it/files/Mozione_Sarpi_Zona1_finale.doc (Accessed 20 June 2008).

Murray, E. 2006, 'Shop Names in English: Support Lost in Translation,' Sydney Morning Herald. 24 October. Online, available: http://www.smh.com.au/news/national/englishonly-a-hardsell/2006/10/24/1161455709410.html (Accessed 14 June 2008).

Nancy, J-L. 1991, The Inoperative Community, trans. P. Connor et al., University of Minnesota Press, Minneapolis.

Neilson, B. \& N. Rossiter 2008, 'Precarity as a Political Concept, or, Fordism as Exception,' Theory, Culture \& Society, vol. 25, no. 7-8, 51-72.

Ong, A. 2005, Neoliberalism as Exception: Mutations in Citizenship and Sovereignty, Duke University Press, Durham, NC, and London. 
Parris, K. 1993, 'Local Initiative and National Reform: The Wenzhou Model of Development,' The China Quarterly, no. 134, 242-63.

Poa, D. \& R. J. LaPolla 2007, 'Minority Languages of China,' in The Vanishing Languages of the Pacific Rim, (eds) O. Miyaoka et al, Oxford University Press, Oxford, 337-54.

Pratt, M. L. 1992, Imperial Eyes: Travel Writing and Transculturation, Routledge, London.

Pun, N. 2005, Made in China: Women Factory Workers in a Global Workplace, Duke University Press, Durham, NC, and London.

Rampini, F. 2006, L'impero di Cinidia, Mondadori, Milano.

Read, J. 2003, The Micro-Politics of Capital: Marx and the Prehistory of the Present, Albany: State University of New York Press.

Sakai, N. 1997, Translation and Subjectivity: On 'Japan' and Cultural Nationalism, University of Minnesota Press, Minneapolis.

Sossi, F. 2007, 'I diversi aspetti delle politiche di conrollo della mobilità: Dall rivolta della communità cinese agli sbarchi di Porto Empedocle,' Melting Pot Europa. Online, available: http://www.meltingpot.org/IMG/mp3/sossi.mp3 (Accessed 18 June 2008).

Thunø, M. 1999, 'Moving Stones from China to Europe: The Dynamics of Emigration from Zhejiang to Europe,' in Internal and International Migration: Chinese Perspectives, (eds) H. Mallee \& F.N. Pieke, Routledge, London, 159-80.

Wang, H. 2003, China's New Order: Society, Politics, and Economy in Transition, trans. T. Huters and R. Karl, Harvard University Press, Cambridge, MA.

Wise, A. 2004, Contact Zones: Experiences of Cultural Diversity and Rapid Neighbourhood Change among Anglo-Celtic and Long Term Elderly Residents in Ashfield, Centre for Research on Social Inclusion, Macquarie University, Sydney.

Xiang, B. 2005, Transcending Boundaries: Zhejiangcan: The Story of a Migrant Village in Beijing, Brill, Leiden. 